\title{
PRODUÇÃO E ACEITABILIDADE DE FERMENTADO DE LARANJA NO ALTO URUGUAI CATARINENSE
}

\section{FERMENTED ORANGE JUICE PRODUCTION AND ACCEPTANCE IN THE WEST OF SANTA CATARINA}

\author{
Poliana Deyse Gurak ${ }^{1}$, Fabiana Bortolini ${ }^{2}$ \\ ${ }^{1}$ Universidade de Contestado - UnC - Concórdia - Brasil poligurak@ hotmail.com \\ ${ }^{2}$ Universidade de Contestado - UnC - Concórdia - Brasil fabi@ uncnet.br
}

\begin{abstract}
Resumo
Este trabalho teve como objetivo a elaboração de fermentados de laranja de diferentes cultivares, a partir de frutas excedentes de produção. O suco de laranja foi chaptalizado a $22 \%$ de sólidos solúveis totais e a fermentação conduzida para a elaboração de fermentado seco e suave. A levedura Saccharomyces cerevisiae foi inoculada aos mostos e as fermentações foram conduzidas em condições de temperatura e pressão ambientais. Após o processo de fermentação, a clarificação foi realizada com terra diatomácea. Os fermentados de laranja foram engarrafados, pasteurizados e conservados a $5{ }^{\circ} \mathrm{C}$. Análises físico-químicas (umidade, extrato etéreo, cinzas, grau Brix, pH, açúcares totais e concentração de etanol) e sensoriais (teste de aceitabilidade) foram realizadas nos produtos finais. Considerando o rendimento teórico de uma fermentação alcoólica $(51,1 \%)$, os fermentados produzidos foram satisfatórios, variando de 39 à $48 \%$. Para os atributos aspecto, sabor, aroma e textura, os tratamentos T1 e T3 (fermentado seco e suave da cultivar pêra, respectivamente) foram superiores. Além disto, a análise sensorial apresentou o índice de aceitabilidade entre 47 a 62\%, o que representa potencial de aceitação e alternativa para pequenas agroindústrias familiares da região Oeste de Santa Catarina.
\end{abstract}

Palavras-chave: fermentado de laranja, caracterização físico-química, análise sensorial.

\section{Introdução}

Diversas frutas apresentam boas características sensoriais para a produção de fermentados e, aliada à necessidade de ampliar suas produções e consumo, a produção de destes fermentados vêm sendo pesquisada e incentivada. É o caso dos fermentados de mangaba (MUNIZ et al., 2002), acerola (SANTOS et al. 2005), caju (TORRES et al., 2006), maçã (FERTONANI et al., 2006), jabuticaba (SILVA et al., 2008), entre outros. Segundo o Decreto n² 2314, 04 de setembro de 1997, estas são bebidas com graduação alcoólica de 4 a $14 \%$ em volume, a $20{ }^{\circ} \mathrm{C}$, obtidas da fermentação do mosto de fruta sã, fresca e madura. 
A laranja é uma das frutas que se presta muito bem à elaboração de fermentado, não só por fornecer um produto de excelente qualidade, quando bem elaborado, mas também por ser uma matéria-prima abundante, largamente difundida e de fácil produção em diferentes regiões.

Em função disso, este trabalho foi desenvolvido em vista das necessidades de pequenos produtores rurais da região do Alto Uruguai Catarinense, que nos períodos de maior produção de laranja nem sempre encontram mercado fácil para a venda das frutas. Neste trabalho foram estudadas a produção e a aceitação sensorial do fermentado de laranja produzidos com as cultivares Valência e Pêra.

\section{Material e Métodos}

O trabalho foi realizado no laboratório de Biotecnologia de Alimentos da Universidade do Contestado - UnC, Concórdia - SC. A matéria-prima utilizada foi laranja excedente de safra, cultivares (cv) Valência e Pêra, isentas de danos mecânicos acentuados, deterioração microbiológica e grau de maturação uniforme. Os frutos foram adquiridos em supermercado de Concórdia (SC) e transportados ao laboratório à temperatura ambiente, durante o inverno (cerca de $15^{\circ} \mathrm{C}$ ) e durante o verão (cerca de $25^{\circ} \mathrm{C}$ ), acondicionados em caixas, lavados em água corrente, cortados e o suco extraído em extrator industrial sofreu uma leve coagem.

As análises físico-químicas realizadas em triplicata nas duas cultivares foram: umidade gravimetria (técnica $\mathrm{n}^{\circ} 22.012$ da AOAC, 1995); extrato etéreo - extração com solvente (técnica ${ }^{\circ}$ 3.122 da AOAC, 1995); cinzas - gravimétrica (técnica $n^{\circ} 22.027$ da AOAC, 1995); grau Brix a 20 ${ }^{\circ} \mathrm{C}$ - por refratometria; $\mathrm{pH}$ - por leitura direta e açúcares totais - pelo método de Felling (ADOLFO LUTZ, 1985).

Os sucos foram submetidos a dois tratamentos diferentes em triplicata para cada cultivar: cv pêra $\left(T_{1}\right)$ e cv valência $\left(T_{2}\right)$ para obtenção de fermentados do tipo seco, e o suco da cv pêra $\left(T_{3}\right)$ e o cv valência $\left(\mathrm{T}_{4}\right)$ para obtenção de fermentados do tipo suave. Todos os tratamento tiveram os teores de sólidos solúveis totais corrigidos para $22 \%$, pela chaptalização, adição de nutrientes (sulfato de amônia 2,0 g/ $10 \mathrm{~L}$ e fosfato de potássio $0,2 \mathrm{~g} / \mathrm{L})$, metabissulfito de potássio $(0,2 \mathrm{~g} / \mathrm{L})$ e leveduras Saccharomyces cerevisiae (4-6 g/L).

A fermentação alcoólica foi conduzida em barriletes de polietileno com capacidade de $5 \mathrm{~L}$, com o volume de trabalho de $3 \mathrm{~L}$, em temperatura ambiente. Todos os fermentados obtidos foram clarificados, maturados e resfriados para posteriores análises físico-químicas e sensorial.

Na tabela 1 estão apresentados os valores de sólidos solúveis, volume de trabalho e nutrientes adicionados para iniciar o processo fermentativo em cada experimento. 
Tabela 1. Fermentação alcoólica do fermentado de laranja com cv Pêra $\left(\mathrm{T}_{1}\right.$ e $\left.\mathrm{T}_{3}\right)$ e Valência $\left(\mathrm{T}_{2}\right.$ e $\left.\mathrm{T}_{4}\right)$.

\begin{tabular}{lcccc}
\hline Quantidades adicionadas & Pêra $\left(\mathbf{T}_{\mathbf{1}}\right)$ & Valência $\left(\mathbf{T}_{\mathbf{2}}\right)$ & Pêra $\left(\mathbf{T}_{\mathbf{3}}\right)$ & Valência $\left(\mathbf{T}_{\mathbf{4}}\right)$ \\
\hline${ }^{\mathrm{o}}$ Brix & 9,4 & 9,6 & 12,0 & 10,5 \\
Quantidade de suco (L) & 3,0 & 3,0 & 3,0 & 3,0 \\
Açúcar adicionado (g/L) & 163 & 161 & 130 & 149 \\
Fosfato de Amônio (g/L) & 0,2 & 0,2 & 0,2 & $0,2 /$ \\
Sulfato de Amônio (g/L) & 0,2 & 0,2 & 0,2 & 0,2 \\
Metabissulfito de K (g/L) & 0,2 & 0,2 & 0,2 & 0,2 \\
Quantidade de fermento (g/L) & 5,5 & 5,5 & 4,0 & 4,0 \\
\hline
\end{tabular}

Durante a fermentação alcoólica foram coletadas alíquotas de $100 \mathrm{~mL}$, em triplicata, a cada doze horas para as determinações da concentração de açúcares totais; concentração de etanol (realizado por ebuliômetro) e pH. Além disso, foram calculados o rendimento e a eficiência da fermentação alcoólica. Após fermentação, os produtos foram trasfegados, clarificados por meio de filtração com terra diatomácea, engarrafados e pasteurizados em batelada por aquecimento em banho-maria a $65{ }^{\circ} \mathrm{C}$ por 30 minutos. Aos produtos finais foi realizada pesquisa de sujidades, segundo a técnica ${ }^{\circ} 44105$ recomendada pela AOAC (1995).

Para a análise sensorial, os atributos avaliados em cada um dos quatro tratamentos foram: aspecto, cor, sabor, aroma e textura, através de um painel semi-treinado composto por quinze avaliadores, utilizando o teste de escala hedônica, que variou entre desgostei muitíssimo (0) até gostei muitíssimo (10) (MONTEIRO, 1984).

A análise estatística para a análise sensorial foi realizada segundo o delineamento de blocos incompletos balanceados, sendo considerados como tratamentos, os fermentados obtidos pelos dois experimentos, avaliados pelos provadores (blocos). O teste de Tukey a $5 \%$ foi aplicado para verificar diferenças significativas entres os produtos (SHIROSE e MORI, 1994). O índice de aceitabilidade foi calculado a partir das médias obtidas no teste de escala hedônica, considerando-se como $100 \%$ a pontuação máxima alcançada (TEIXEIRA et al., 1987). Os fermentados considerados aceitáveis em termos de suas propriedades sensoriais, são os que obtêm um índice de aceitabilidade de no mínimo 50 \% (MONTEIRO, 1984).

\section{Resultados e Discussão}

Na tabela 2 estão indicados os dados da composição centesimal dos sucos cv Pêra e Valência antes de iniciar o processo fermentativo.

Verificou-se uma diferença entre as cultivares em relação aos açúcares não redutores expressos em sacarose e isso favoreceu um comportamento diferente durante a fermentação tumultuosa. 
Tabela 2. Análise da composição centesimal da laranja cv Pêra e Valência.

\begin{tabular}{lcc}
\hline Análise & cv Pêra & cv Valência \\
\hline Umidade (\%) & 88,5 & 86,6 \\
Cinzas amostras seca (\%) & 1,0 & 1,1 \\
Cinzas amostra úmida (\%) & 0,1 & 0,2 \\
Fibras (\%) & 0,9 & 0,8 \\
Grau Brix & 13,5 & 13,6 \\
pH mosto & 3,7 & 3,6 \\
pH suco & 3,4 & 3,2 \\
Açúcares redutores em glicose (\%) & 6,3 & 6,0 \\
Açúcares totais (\%) & 11,5 & 12,6 \\
Açúcares não redutores sacarose (\%) & 4,9 & 7,2 \\
\hline
\end{tabular}

\section{Acompanhamento das fermentações alcoólicas}

Os resultados do acompanhamento da fermentação (ensaios $T_{1}$ e $T_{2}$ ) estão apresentados na Tabela 3. A fermentação tumultuosa durou 120 horas. Após este período foi possível obter produtos com teor de açúcares redutores inferior a 1,5, o que indica que as leveduras transformaram eficazmente a glicose presente mosto em etanol. Para obtenção de $10 \mathrm{~L}$ de suco de cada tratamento foi utilizado 27,3 Kg de laranja cv pêra, e 23,6 Kg da cv valência, obtendo-se um volume de mosto muito próximo, de $10,10 \mathrm{~L}$ e $9,91 \mathrm{~L}$, o que indicou um rendimento de $37 \%$ e $42 \%$, respectivamente, variação decorrente da cultivar utilizada no processo. Corazza et al. (2001), realizando fermentado de laranja obteve um rendimento ainda maior (56\%) utilizando a cv pêra.

Tabela 3. Acompanhamento da fermentação alcoólica para a obtenção de fermentado seco com a cv pêra $\left(T_{1}\right)$ e valência $\left(T_{2}\right)$.

\begin{tabular}{lcccccc}
\hline \multirow{2}{*}{$\begin{array}{l}\text { Tempo } \\
\text { (horas) }\end{array}$} & \multicolumn{3}{c}{ Pêra $\left(\mathrm{T}_{1}\right)$} & \multicolumn{3}{c}{ Valência $\left(\mathrm{T}_{2}\right)$} \\
\cline { 2 - 7 } & Açúcares redutores (\%) & Teor alcoólico $(\%)$ & $\mathrm{pH}$ & Açúcares redutores $(\%)$ & Teor alcoólico $(\%)$ & $\mathrm{pH}$ \\
\hline 0 & 22,0 & 0 & 3,9 & 22,0 & 0 & 3,7 \\
24 & 15,7 & 0,1 & 4,0 & 16,6 & 1,0 & 3,9 \\
48 & 8,7 & 5,6 & 3,8 & 10,8 & 4,5 & 3,7 \\
72 & 3,1 & 9,2 & 3,9 & 4,8 & 3,4 & 3,8 \\
96 & 0,9 & 10,0 & 3,8 & 3,5 & 9,8 & 3,7 \\
120 & 0,4 & 10,0 & 4,0 & 1,5 & 3,9 \\
\hline
\end{tabular}

$\mathrm{O}$ vinho obtido no $\mathrm{T}_{1}$, ao final da fermentação alcoólica (120 horas), apresentou teor de açúcares redutores de $0,4 \%$, teor alcoólico de $10,0 \%, \mathrm{pH}$ de 3,9, rendimento de $46 \%$ e eficiência fermentativa de $91 \%$. Enquanto que o $\mathrm{T}_{2}$ apresentou $1,5 \%$ de açúcares redutores, 9,8\% de teor alcoólico, 3,8 de pH, $48 \%$ de rendimento e $94 \%$ de eficiência fermentativa. O teor residual de açúcares remanescentes deve-se a presença de açúcares não fermentescíveis presentes no mosto de laranja, também observado por Corazza et al. (2001) na produção de fermentado de laranja e também em fermentado de acerola (EVANGELISTA et al., 2005) e de jaca (ASQUIERI et al., 2008). 
No segundo experimento, objetivando atingir um fermentado de laranja suave, foram seguidos os mesmos procedimentos do experimento descrito anteriormente. Para esta fermentação utilizou-se 24,4 Kg da cv pêra e 24,6 Kg da cv valência, obtendo-se $10 \mathrm{~L}$ de suco de cada cultivar. A cv pêra nesta extração do suco teve um rendimento de $41 \%$, enquanto que o cv valência $43 \%$.

A fermentação alcoólica, a mais importante na fabricação do fermentado, abrange toda a etapa desde o preparo do inóculo até a etapa de trasfega. No processo de fermentação, podem ser distinguidas três fases: preliminar, de adaptação da cultura ao meio; tumultuosa e a fase complementar, o fim da fermentação. A fermentação compreende um conjunto de reações enzimaticamente controladas, através das quais uma molécula orgânica é degradada em compostos mais simples liberando energia (CORAZZA et al., 2001).

Os resultados do acompanhamento da fermentação tumultuosa do segundo experimento estão apresentados na Tabela 4. Ao final de 36 horas o fermentado da cv pêra apresentou teor de açúcares redutores de 3,9\%, teor alcoólico de 7,8\%, pH de 4,06, rendimento de $39 \%$ e eficiência fermentativa de $77 \%$. A cv valência apresentou 3,8\% de açúcares redutores, teor alcoólico de 7,3 $\%, \mathrm{pH}$ de 3,70 , rendimento de $40 \%$ e eficiência fermentativa de $79 \%$.

Tabela 4. Acompanhamento da fermentação alcoolica nos tratamentos com a cv pêra $\left(\mathrm{T}_{3}\right)$ e valência $\left(\mathrm{T}_{4}\right)$.

\begin{tabular}{lcccccc}
\hline \multirow{2}{*}{$\begin{array}{c}\text { Tempo } \\
\text { (horas) }\end{array}$} & \multicolumn{3}{c}{ Pêra $\left(\mathrm{T}_{3}\right)$} & \multicolumn{3}{c}{ Valência $\left(\mathrm{T}_{4}\right)$} \\
\cline { 2 - 7 } & Açúcares redutores (\%) & Teor alcoólico (\%) & $\mathrm{pH}$ & Açúcares redutores $(\%)$ & Teor alcoólico $(\%)$ & $\mathrm{pH}$ \\
\hline 0 & 24,0 & 0 & 4,2 & 22,0 & 0 & 4,0 \\
12 & 10,1 & 0,5 & 4,0 & 9,0 & 0,3 & 3,8 \\
24 & 6,0 & 5,2 & 3,9 & 6,5 & 2,6 & 3,8 \\
36 & 3,9 & 7,8 & 4,1 & 3,8 & 7,3 & 3,7 \\
\hline
\end{tabular}

O primeiro experimento apresentou uma fermentação mais lenta, ao fato do mesmo ter sido realizado no inverno (temperatura ambiente de $\pm 15^{\circ} \mathrm{C}$ ). Já no segundo experimento, por ter sido realizado no verão (temperatura ambiente de $\pm 25^{\circ} \mathrm{C}$ ), a fermentação foi mais rápida, em cerca de $40 \%$ do tempo da primeira fermentação. Porém, o efeito da temperatura não foi considerado variável do processo. Mesmo assim, é sabido que baixas temperaturas permitem obter alto rendimento em álcool, não somente pela fermentação mais completa, mas também por minimizar a perda por evaporação, além da influência na velocidade da fermentação e na natureza e quantidade de compostos secundários formados (AQUARONE e ZACANARO JUNIOR, 1983).

$\mathrm{O}$ pH durante o processo fermentativo sofreu uma pequena variação, devido às propriedades tamponantes existentes no mosto da fruta e no fermentado, abaixando durante o processo em pequena proporção por ação das leveduras que convertem o açúcar presente no mosto em álcool e ácidos orgânicos (MUNIS, 2002). Corazza et al. (2001), durante a condução da fermentação alcoólica também não verificou muita variação- entre 3,60 e 3,33. 


\section{Análise dos produtos finais obtidos}

As análises do índice de acidez total, resíduo seco a $105^{\circ} \mathrm{C}$, cinzas, teor alcoólico, análise microscópica e sensorial foram realizadas para avaliação do produto final. $\mathrm{Na}$ análise microscópica não foram detectadas sujidades e/ou microrganismos em nenhum tratamento analisado. Na determinação da acidez total, que quantifica diversos ácidos orgânicos presentes na forma livre, sendo os mais importantes o ácido tartárico, o ácido málico e o ácido láctico total, os fermentados $\mathrm{T}_{2}$ e $\mathrm{T}_{4}$ apresentaram valores superiores, bem como para a análise do $\mathrm{pH}$ durante toda a fermentação.

A acidez total fornece somente a soma de ácidos livres, sem levar em conta a sua formação e não define suficientemente a acidez. Por outro lado, a acidez real ou a concentração de íons hidrogenados $\mathrm{H}^{+}$, representados pelo $\mathrm{pH}$, é uma relação entre a quantidade e a força de ácidos, representada pela sua constante de dissociação de íons $\mathrm{H}^{+}$. $\mathrm{O}$ valor de concentração de íons $\mathrm{H}^{+}$nos fermentados é da ordem de 0,001 a 0,0001 g/L. Convertido em pH, esse valor é exatamente o cologaritmo da concentração de íons $\mathrm{H}^{+}$, que representa 3 a 4. Por isso, o fermentado com $\mathrm{pH} 3,4$ apresentou melhor resistência a infecções bacterianas (AQUARONE, 2001).

$\mathrm{Na}$ determinação do resíduo seco a $105{ }^{\circ} \mathrm{C}$, que permanece após a evaporação dos compostos voláteis sob condições físicas determinadas, $\mathrm{T}_{1}$ foi superior. Para o teor de cinzas $\mathrm{T}_{3}$ e $\mathrm{T}_{4}$ apresentaram valores superiores. Segundo Vogt et al. (1986), as substâncias minerais encontradas em pequenas quantidades no vinho são o ferro, o cobre, o zinco, o magnésio,o chumbo e o alumínio.

Em relação ao teor de açúcares os tratamentos apresentaram-se como: $\mathrm{T}_{1}$ : seco $\mathrm{T}_{2}$ : meio seco $\mathrm{T}_{3}$ e $\mathrm{T}_{4}$ suaves, os quais podem apresentar de 1 a $4 \%$ de açúcares nos produtos finais. Em relação ao teor alcoólico, $\mathrm{T}_{2}, \mathrm{~T}_{3}$ e $\mathrm{T}_{4}$ não se enquadram-se dentro da faixa determinada pelo MAPA (10 a 13 ${ }^{\circ} \mathrm{GL}$ ) (BRASIL, 1988). Teores alcoólicos inferiores a $10{ }^{\circ} \mathrm{GL}$ para fermentado de outras frutas também também foram encontrados na literatura, é o caso de fermentados de maçã (FERTONANI et al., 2006) e mangaba (MUNIZ et al., 2002).

Tabela 5. Análises dos produtos finais obtidos nos dois experimentos: $\mathrm{T}_{1}$ e $\mathrm{T}_{2}$ (primeiro experimento); $\mathrm{T}_{3}$ e $\mathrm{T}_{4}$ (segundo experimento).

\begin{tabular}{lcccc}
\hline Análise & $\mathrm{T}_{1}$ & $\mathrm{~T}_{2}$ & $\mathrm{~T}_{3}$ & $\mathrm{~T}_{4}$ \\
\hline Sujidades & ausência & ausência & ausência & ausência \\
Acidez total (\%) & 1,12 & 1,56 & 1,13 & 1,38 \\
Resíduo seco (\%) & 6,85 & 5,78 & 3,95 & 3,76 \\
Umidade (\%) & 93,1 & 94,2 & 96,0 & 96,2 \\
Cinzas (úmida) & 9,41 & 5,38 & 10,38 & 10,03 \\
Álcool etílico (\%) & 10,1 & 9,7 & 7,9 & 7,3 \\
Açúcares redutores (\%) & 0,38 & 1,56 & 3,96 & 3,48 \\
pH & 3,97 & 3,85 & 4,06 & 3,70 \\
Rendimento (\%) & 46,51 & 48,03 & 39,26 & 40,43 \\
Eficiência fermentativa (\%) & 91,03 & 94,03 & 76,82 & 76,09 \\
\hline
\end{tabular}


Os rendimentos e eficiências fermentativas foram superiores nos tratamentos $T_{1}$ e $T_{2}$, pois os demais permaneceram com teor de açúcares residual superior, o que favoreceu percentuais menores de rendimento e eficiências fermentativas.

\subsection{Análise sensorial}

Os resultados da análise sensorial estão apresentados na Tabela 6. Para o atributo aspecto, os valores médios encontrados foram de $58 \%$ para ambos os tratamentos não apresentando diferenças significativas. Para o atributo cor, avaliado apenas pela observação visual, os valores médios encontrados foram 52,7, 56,7, 55,1 e 57,5\%, para $\mathrm{T}_{1}, \mathrm{~T}_{2}, \mathrm{~T}_{3}$ e $\mathrm{T}_{4}$, havendo diferenças significativas, sendo $\mathrm{T}_{1}$ inferior neste atributo. Para o atributo sabor, os valores médios foram: 61,0, 47,0, 63,4 e 49,1\%, para $\mathrm{T}_{1}, \mathrm{~T}_{2}, \mathrm{~T}_{3}$ e $\mathrm{T}_{4}$, sendo que o $\mathrm{T}_{2}$ e $\mathrm{T}_{4}$ diferem significativamente ao nível de $5 \%$ do $\mathrm{T}_{1} \mathrm{e}$ $\mathrm{T}_{3}$. Para o atributo aroma, os valores médios foram: 57,3, 48,7, 53,3 e 51,3, para $\mathrm{T}_{1}, \mathrm{~T} 2, \mathrm{~T}_{3}$ e $\mathrm{T}_{4}$, sendo $\mathrm{T}_{2}$ inferior significantemente aos demais. Para o atributo textura, $\mathrm{T}_{1}: 62,7, \mathrm{~T}_{2}: 54,7, \mathrm{~T}_{3}: 61,1 \mathrm{e}$ $\mathrm{T}_{4}$ : 50,2, também houveram diferença significativa entre os tratamentos, sendo que mais uma vez os tratamentos com as cultivares valência foram inferiores. Verificou-se que para todos os atributos, exceto cor, os tratamentos com a cultivar pêra foram superiores.

Tabela 6. Avaliação do Índice de aceitabilidade dos produtos obtidos nos dois experimentos.

\begin{tabular}{ccccc}
\hline Atributo & $\mathrm{T}_{1}$ & $\mathrm{~T}_{2}$ & $\mathrm{~T}_{3}$ & $\mathrm{~T}_{4}$ \\
\hline Aspecto & 59,0 & 59,0 & 58,0 & 53,0 \\
Cor & 52,7 & 56,7 & 55,1 & 57,5 \\
Sabor & 61,0 & 47,0 & 63,4 & 49,1 \\
Aroma & 57,3 & 48,7 & 53,3 & 51,3 \\
Textura & 62,7 & 54,7 & 61,1 & 50,2 \\
\hline
\end{tabular}

Em relação ao índice de aceitabilidade foi verificado que para o atributo aspecto e cor, todos apresentaram índice de aceitabilidade acima de $50 \%$, o que caracteriza um produto aceito ao nível de consumidor. Para o atributo sabor, $\mathrm{T}_{2}: 47 \%$ e $\mathrm{T}_{4}: 49,1 \%$ foram rejeitados pelo índice de aceitabilidade. Para o atributo aroma, apenas o $\mathrm{T}_{2}(48 \%)$ foi rejeitado e para o atributo textura, todos os tratamentos apresentaram valores acima de $50 \%$.

Os tratamentos $\mathrm{T}_{2}$ e $\mathrm{T}_{4}$ foram reprovados em alguns atributos. Podem ser consideradas para isso algumas características, como a elevada acidez da fruta e o maior tempo necessário para a conversão de açúcar em álcool. A fermentação do açúcar pelas leveduras conduz não apenas à formação de álcool como produto principal, mas também à produção de vários produtos secundários. Entre esses produtos secundários, alguns são desejáveis como o glicerol, e outros indesejáveis, como o sulfeto de hidrogênio, não determinados no trabalho.

No trabalho de Sato et al. (2006) a análise sensorial realizada em fermentado de laranja clarificado mostrou que os provadores tiveram pequenas restrições quanto ao paladar dos 
fermentados alcoólicos, considerando-os muito secos, os quais apresentaram 16,1 \% (v/v) de teor alcoólico e 1,0\% (v;v) de açúcar residual.

\title{
4 Considerações Finais
}

Os produtos finais apresentaram qualidade artesanal, com características físico-químicas próprias para consumo. As análises sensoriais indicaram que os fermentados com maior aceitação foram elaborados com a cultivar pêra.

\section{Agradecimentos}

Fundo de Apoio a Pesquisa (FAP-UnC).

\begin{abstract}
This work aimed to making of orange fermented from surpluses out of the processing of the orange fruit juice. The orange juice was chaptalize with $22 \%$ of soluble solids. At the must was inoculated the Saccharomyces cerevisiae yeast and fermentation was carried in environment condition of temperature and pressure. After full fermentation, the clarification was realized with diatomaceous earth. The orange fermented were packed into glass bottle, pasteurized and conserved at $5{ }^{\circ} \mathrm{C}$ and physical, chemical and sensorial analysis was made. The fermentation produced had high yields, low costs, and organoleptically suitable for consumption. The sensory analysis showed the rate of acceptability between 47 to $62.7 \%$. In addition, the fermentation had a high yield and low cost is a great alternative for small agro industries.
\end{abstract}

Key-words: orange wine, chemical characterization, sensorial analysis.

\section{Referências}

ASQUIERI, E. R, RABÊLO, A. M. S., SILVA, A. G. M. Fermentado de jaca: estudo das características físico-químicas e sensoriais. Ciência e Tecnologia de Alimentos, v. 28, n. 4, Campinas, 2008. DOI: 10.1590/S010120612008000400018.

AQUARONE, E., ZANCANARO JÚNIOR, O. Vinagres. In: AQUARONE, E., LIMA, U. A., BORZANI, W. (coords). Alimentos e bebidas produzidos por fermentação. v. 5.São Paulo: Edgard Blücher, 1983.

AQUARONE, E.; et al. Biotecnologia Industrial. vol. 5. São Paulo: Edgard Blücher, 2001.

ASSOCIATION OFFICIAL ANALYTICAL CHEMIST. Official methods of analysis of the Association of Analytical Chemist., 16. ed., Arlington : Sidney William, 1268 p. 1995.

BRASIL. Decreto n ²314, 04 de setembro de 1997. Diário Oficial da União, DF, 31/10/1988.

BRASIL; Portaria n ²29, 25 outubro de 1988,. Diário Oficial da União, DF, 31/10/1988.

CORAZZA, M. R., RODRIGUES, D. G. E NOZAKI, J. Preparação e caracterização do vinho de laranja. Química Nova, v. 24, n. 4, p. 449-452, 2001. DOI: 10.1590/S0100-40422001000400004.

EVANGELISTA, A. F., ALMEIDA. S., SANTANA, J. C., SOUZA, R. R. Avaliação RSM de fatores que influenciam na produção de vinho de acerola. Brazilian Journal of Food Technology. $5^{\circ}$ Sipal, p. 8-13. 2005. 
FERTONANI, H. C. R.; SIMÕES, D. R. S.; NOGUEIRA, A.; WOSIACKI, G. Potencial da variedade Joaquina para o processamento de suco clarificado e vinho seco de maçã. Ciência e Tecnologia de Alimentos, v. 26, n. 2, p. 434-440, 2006. DOI: 10.1590/S0101-20612006000200029.

INSTITUTO ADOLFO LUTZ. Normas analíticas: métodos químicos e físicos para análise de alimentos. 3. ed. São Paulo, p. 281-283. 1985.

MONTEIRO, C. L. B. Análise sensorial: seleção e treinamento de equipes de degustadores. Boletim CEPPA, Curitiba, v. 2, n. 1, 1984 .

MUNIZ, C. R.; BORGUES, M. F.; ABREU, F. A. P.; NASSAU, R. T.; FREITAS, C. A. S. Bebidas fermentadas a partir de frutos tropicais. Boletim CEPPA, v. 20, n. 02, p. 309-322. 2002.

SANTOS, S. C; ALMEIDA, S. S.; TOLEDO, A. L.; SANTANA, J. C. C.; SOUZA, R. R. Elaboraçao e análsie sensorial do fermentado de acelora (Malpighia Puncifolia L.) Brazilian Journal Food Technology, $5^{\circ}$ Sipal, p. $47-50$. 2005 .

SATO, C. R. O.; REIS, R. G; LIMA, U. A. Uso de pectinase na clarificação de mostro fermentado de laranja. Higiene Alimentar, v. 20, n. 143, p. 42-44. 2006.

SHIROSE, I., MORI, E. E. M. Estatística aplicada à análise sensorial. Campinas : ITAL, v. 1, 73 p. 1994. (Manual Técnico do Instituto de Tecnologia de Alimentos).

SILVA, P. H. A.; FARIA, F. C.; TONON, B.; MOTA, J. D.; PINTO, V. T. Avaliação da composição química de fermentados alcoólicos de jabuticaba (Myrciaria jabuticaba). Química. Nova, v. 31, n. 3, p. 595-600, 2008. DOI: 10.1590/S0100-40422008000300025.

TEIXEIRA, E., MEINERT, E. M., BARBETTA, P.A. Análise sensorial de alimentos. Florianópolis : UFSC, 180 p. 1987

TORRES, A. B.; SILVA, M. E.; SILVA, W. B.; SWARNAKAR, R.; SILVA, F. L. H. Cinética e caracterização físicoquímica do fermentado do pseudofruto do caju (Anacardium occidentale L.). Química. Nova, v. 29, n. 3, p. 489-492, 2006. DOI: 10.1590/S0100-40422006000300015.

VOGT, E.; JAKOB, L.; LEMPERLE, E.; WEISS, E. El vino: obtención, elaboración e análisis. Zaragoza: Acribia,. 1986.

\section{Dados dos autores}

Nome completo: Poliana Deyse Gurak

Filiação institucional: Universidade do Contestado

Departamento: Química Industrial de Alimentos

Função ou cargo ocupado: Estudante

Titulação: Química Industrial de Alimentos

Endereço: Fundação Universidade do Contestado. Rua Victor Sopelsa, 3000. Bairro Salete. CEP 89700-000 - Concórdia, SC. Telefone: (49) 34411097 Fax: (49) 4800.

e-mail:poligurak@hotmail.com

Nome completo: Fabiana Bortolini

Filiação institucional: Universidade do Contestado

Departamento: Química Industrial de Alimentos

Função ou cargo ocupado: Professora

Titulação: Engenheira Agrônoma

Endereço: Fundação Universidade do Contestado. Rua Victor Sopelsa, 3000. Bairro Salete. CEP 89700-000 - Concórdia, SC. Telefone: (49) 34411097 Fax: (49) 4800.

e-mail:fabi@uncnet.br 